\title{
Letters
}

Website: bmj.com

Email: letters@bmj.com

\section{MMR vaccine uptake may be lower than reported because of manipulation of target groups}

EDITOR-One issue seems to have been completely ignored in the current debate on vaccination against measles, mumps, and rubella (MMR). The average uptake of the MMR vaccine across England now stands officially at $84 \%$, some way off the recommended target of $95 \%$. Although this rate is of considerable concern in itself, vaccine uptake may be even lower than reported.

Falling rates of vaccine uptake and the subsequent loss of income experienced by several general practices failing to reach payment targets have prompted some general practitioners to take unusual measures. They have temporarily removed children whose parents object to vaccination with MMR vaccine from their lists immediately before they would have been included in the target group for vaccination. These children are therefore excluded from the denominator for calculating vaccine uptake. The general practitioners concerned write to parents informing them of the "temporary measure" and undertake to provide all usual services to these children at no cost. The immediate result is that vaccine uptake appears artificially high and general practitioners receive payment for reaching vac-

\section{Advice to authors}

We prefer to receive all responses electronically, sent directly to our website. Processing your letter will be delayed unless it arrives in an electronic form.

We are now posting all direct submissions to our website within 24 hours of receipt and our intention is to post all other electronic submissions there as well. All responses will be eligible for publication in the paper journal.

Responses should be under 400 words and relate to articles published in the preceding month. They should include $\leqslant 5$ references, in the Vancouver style, including one to the BMJ article to which they relate. We welcome illustrations.

Please supply each author's current appointment and full address, and a phone or fax number or email address for the corresponding author. We ask authors to declare any competing interest. Please send a stamped addressed envelope if you would like to know whether your letter has been accepted or rejected.

Letters will be edited and may be shortened.

bmj.com

letters@bmj.com cine targets. After the payment deadline is passed the patients are accepted back on to the list.

As a result of this manipulation of vaccine coverage the population may be at even greater risk of a measles outbreak than has been previously supposed. Furthermore, because these patients are not registered, capitation payments to primary care trusts may be reduced leading to a loss of health care for local people. Such action continues in this health authority area, despite strong advice against it from the Department of Health, the health authority, and the local medical committee. The General Medical Council has written that as long these patients are treated on the same footing as other NHS patients, the doctors' conduct will not give rise to ethical objections from the council. Thus general practitioners engaged in this practice see no reason to stop.

Although the Department of Health may be correct in its decision to persevere with the MMR vaccine, it is time to review how vaccine target payments are calculated. The Department of Health could consider practices that pool risk. One partner in a practice could carry the financial burden of patients who decline vaccination: currently targets are calculated for the practice. The department could consider accepting a written disclaimer from patients as acceptance that a practice has made every effort to vaccinate the children concerned.

While the current doubts about MMR vaccine, however unfounded, continue, this manipulation of target figures is likely to increase, leading to more uncertainty about the accuracy of vaccine coverage, and in effect placing the population at greater risk. Thomas J Scanlon consultant in public health medicine

East Sussex, Brighton and Hove Health Authority, Lewes, East Sussex BN7 2PB toms@esbhhealth.cix.co.uk

\section{MMR vaccine debate}

Debate crystallises dilemma facing many medical disciplines

EDIToR-Tom Heller articulates the dilemma facing doctors in many medical disciplines in his article in the ethical debate on measles, mumps, and rubella (MMR) vac- cine, a debate that is being stifled because of the overwhelming evidence base in favour of immunisation. ${ }^{1}$ He reaches the core of the debate when he refers to the balance to be struck between informed consent and the right of the state to control an infectious disease. He may feel uncomfortable because he is caught between two roles: that of the agent of the state, which doctors are often unwittingly asked to be, and that of protecting the best interest of his patients.

After Alder Hey and Bristol a lot of noise has been made centrally about the need to put patients first and reverse what is seen as the historical imbalance in power between doctors and clients, as Pattison points out in the final paragraph of his contribution to the debate. ${ }^{1}$ The need for a power differential between experts and clients and for an implicit contract between the parties in terms of who delivers the expertise is currently out of vogue.

If the profession is to be shaken into putting patients first, how does it also put evidence or central government directives first? Doing it surreptitiously by payments for immunisation targets helps no one. Therefore, in its attempt to put patients first the government will presumably now revoke immunisation targets and reincorporate the monies into general practitioners' basic remuneration-still time to include this in the new contractual arrangements.

If not, then it will presumably support giving doctors time to prepare their own leaflets on the available evidence, individualise their patient care, and then state that once informed it is entirely up to parents to decide on the best course of action for their child.

The only other way to extract clinicians from this mire would be to separate the functions of patient advocacy and protection from central pronouncements and evidence based medicine. This might lead to the evolution of new professions: those of expert (remunerated) patient advocates accompanying patients to consultations. It could also lead to two types of doctors: those trained in evidence based medicine and those trained in person centred medicine. They would work in pairs and debate issues in front of patients, who would then decide. This already happens in the postmodern world of family therapy, in the "reflecting team" approach. ${ }^{2}$ It would cost more, but it might allow people to reoccupy positions of expertise that are reconcilable and put patients where the government wants them: in the driving seat. Of course they might have to take responsibility for their deci- 
sions, and what would that do to the system in which people sue for negligence?

Richard Fry child and family psychiatrist

Child Family and Adolescent Consultation Service, Uxbridge, Middlesex, UB8 1BN

Richard.Fry@hhh-tr.nthames.nhs.uk

Competing interests: None declared.

1 Heller T, Heller D, Pattison S, Heller T. Ethical debate: Vaccination against mumps, measles, and rubella: is there a case for deepening the debate? BMJ 2001;323:838-40. (13 October.)

2 Andersen T. The reflecting team: dialogue and metadialogue in clinical work. Family Process 1987;26:415-28.

General practitioners' two roles are not in conflict with MMR immunisation

EDITOR-I am intrigued by Fry's statement in his electronic response to the ethical debate on measles, mumps, and rubella (MMR) vaccine (letter printed above) that general practitioners are caught between being agents of the state and protecting the best interests of their patients..$^{12}$ To my mind, at least when it comes to immunisation against measles, mumps, and rubella, there is no problem at all: by encouraging MMR immunisation, doctors are protecting the best interests of their patients. The patient in front of the general practitioner may be more likely to benefit than be harmed by the vaccination.

In addition, the population benefits are notable. Because measles is so infectious, a high uptake of MMR vaccine is necessary to maintain herd immunity. If rates drop to, say, $60 \%$, then herd immunity will be lost, and nearly all of the vulnerable $40 \%$ will get measles. There are over 600000 births per year, so about 240000 children would get measles each year, and, taking Dick Heller's more conservative figure, ${ }^{2}$ we should consequently expect to see 240 deaths.

Peter M B English consultant in communicable disease control

Surrey Communicable Disease Control Service, East Surrey Health Authority, Epsom, Surrey KT19 8PH

peter_english@bigfoot.com

Competing interests: None declared.

1 Fry R. MMR: Caught betweeen stools. Electronic response to Ethical debate: Vaccination against mumps, measles, and rubella: is there a case for deepening the debate? bmj.com 2001 (www.bmj.com/cgi/eletters/323/7317 838\#16953; accessed 13 March 2002.

2 Heller T, Heller D, Pattison S, Heller T. Ethical debate: vaccination against mumps, measles, and rubella: is there case for deepening the debate? $B M J 2001 ; 323: 838-40$. (13 case for deepening the debate? BMJ 2001;323:838-40. (13 October)

\section{Single measles vaccine should be allowed} EDITOR-The controversy surrounding measles, mumps, and rubella (MMR) vaccine will not go away. The title of the series of articles poses the question whether there is a case for deepening the debate. ${ }^{1}$ I believe that there is. Many of us are not in a position to evaluate critically all the evidence presented and are further confused to find that well qualified experts stand in both camps of the debate.

From the infant's perspective, immunisation against measles seems the most pressing as infection carries a small risk of serious and even fatal complications.
Mumps and rubella are far less serious for infants, and my understanding is that the only scientific argument for immunising infants against these two diseases is to establish a good herd immunity, which will benefit society and reduce infections of nonimmune older children and adults, in whom sequelae of mumps and rubella can be more serious. I can also see the practical and economic reason for providing an immunisation against more than one disease in a single vaccine. But should the benefit to society take precedence over possible risks to an individual? My understanding of Wakefield's hypothesis is that in a very small number of children the triple vaccine may precipitate Crohn's disease or autism. ${ }^{2}$

What I find puzzling is the adamant refusal of the authorities to facilitate the availability of the single measles vaccine, to the point that the Department of Health has banned its use in the NHS. How does this fit with the growing acceptance of patients autonomy and choice? It is now enshrined in case law that a pregnant women can, for rational or irrational reasons, refuse treatment even if that refusal fatally jeopardises her unborn child.

The medical profession should support a parent's wish to be given single vaccines, however irrational the establishment might view that wish. There are some parents who are opposed to the rubella component of MMR, because of its manufacture on cell lines extracted from aborted fetuses, but who would still wish their child to be immunised using single vaccines available in other countries. The arguments against use of single vaccines on grounds of safety and efficacy are weak and difficult to accept, particularly when other countries with equivalent medical and ethical standards make them freely available.

Michael Jarmulowicz master, Guild of Catholic Doctors

Roval Free Hospital, London NW3 2OG Michael.Jarmulowicz@rfh.nthames.nhs.uk

Competing interests: None declared.

1 Heller T, Heller D, Pattison S, Heller T. Ethical debate: Vaccination against mumps, measles, and rubella: is there case for deepening the debate? BMJ 2001:323:838-40. (13 October.)

A, Murch S, Anthony A, Linnell J, Casson D, Wakefield A, Murch S, Antony A, Lin J, Casson D, Malk $M$, et al. Ileal-ymphoid nodular hyperplasia, in children Lancet 1998:351:1327-18.

\section{There is no room for lingering doubt}

EDITOR-We write to commend and complain, with reference to the debate on the safety of measles, mumps, and rubella (MMR) vaccine from a primary care perspective. ${ }^{1}$ Ethical debate is a central part of the jigsaw of developing patient care and may serve as the patient's (in)visible advocate. But we question the wisdom, not in commissioning the debate, but in publishing the anecdotal response of Heller, who has lingering doubts about the safety of this vaccine. Such a reply risks indoctrinating some parents as the final word on the subject.

In paediatrics and primary care the uphill battle to increase vaccine uptake seems to get increasingly difficult. Countless, perhaps excessive, hours are currently expended in both primary and secondary care counselling parents about the safety of the vaccine. This is not because they are awkward, ignorant, or ambiguous, more because they are becoming more "informed." Some of their information comes from the popular press or online information sources, including the well known flawed research by Wakefield et al. ${ }^{2}$ Furthermore, the $B M J$ is one of the most frequently quoted in the popular press and available to all online.

The list of professional groups that endorse the vaccine is exhaustive. ${ }^{3}$ Why then publish alongside it at best anecdotal evidence from one general practitioner that he has lingering doubts about the safety of the vaccine? This adds nothing constructive in the way of ethical debate and only serves to scaremonger.

Informed refusal must remain an acceptable choice, but the overwhelming evidence currently available is that the vaccine is safe. Until there is evidence to the contrary we in the medical profession must unite and encourage vaccine uptake. It is not a case of keeping one's head down, simply good practice. The Children Act 1989 highlights parental responsibility. We as healthcare providers would do well to follow this dogma in the setting of MMR vaccination. We have a responsibility to endorse it emphatically; any less is a failure and a breach of our terms of service, visible or invisible.

The personal view by Morris tucked away towards the back of the same edition painted the darker side of measles in the context of subacute sclerosing panencephalitis. ${ }^{4}$ Honest yes, scaremongering no. In the setting of MMR vaccine, we need more of this and less of the lingering doubt.

Nick Barnes specialist registrar, paediatrics Royal Berkshire Hospital, Reading RG1 5AN nickbarnes10@hotmail.com

Elizabeth James general practitioner Didcot Health Centre, Didcot OX11 7JN

Competing interests: None declared.

1 Heller T, Heller D, Pattison S, Heller T. Ethical debate: Vaccination against mumps, measles, and rubella: is there case for depening the debate? BMJ 2001;323:838-40. (19 case for

2 Wakefield A, Murch S, Anthony A, Linnell J, Casson D, Malik M, et al. Ileal-lymphoid nodular hyperplasia, Malik M, et al. Ileal-lymphoid nodular hyperplasia $51: 1327-18$

3 CSM/MCA. Current problems in pharmacovigilance 2001;27:3

4 Morrison L. Measles-a minor childhood illness? BMJ 2001;323:875. (13 October.)

\section{Competing interests need to be declared}

EDITOR-Tom Heller asks what we are to make of researchers who declare funding from drug manufacturers involved in manufacturing vaccines. ${ }^{1} \mathrm{He}$ and others deserve a general answer as there is a danger that such declarations may be being misunderstood.

Virtually all new vaccines in use in developed countries today are made by commercial companies. These vaccines have to be put through clinical trials (usually in children) to demonstrate safety and efficacy 
before licensure, the costs of which are paid for by the manufacturers. Such studies are done by doctors, and it is desirable that these doctors should be independent rather than employees of the companies. Thus their aims should be to conduct only scientifically sound studies and protect the subjects enrolled, rather than make a profit for the company. It is therefore standard practice that agreements between such researchers and sponsoring companies exclude the researchers from personal financial gainfor example, through investment in the sponsoring company.

Nevertheless, a result of this system is that virtually all clinical research studies on new drugs and vaccines coming to licensure are commercially funded. The professional success of clinical researchers depends pringenerate. Thus researchers-although they are usually not receiving personal financial inducements-have a competing interest, which they correctly declare.

Readers should interpret such declarations as a qualification to give a well informed opinion, as anyone unable to declare such competing interests is unlikely ever to have had any direct experience of using new vaccines in children. The main advantage of the system is, however, that it promotes transparency. Clinical researchers (and editors) are leading the way here, and other authors should start to consider how they too can declare the interests and motives that underlie the opinions they express in public.

Adam Finn professor of paediatrics Institute of Child Health, University of Bristol, Bristol BS2 8DJ

Adam.Finn@bristol.ac.uk

Competing interests: $\mathrm{AF}$ has received substantial funding for research and academic activities from virtually all vaccine manufacturers during the past five years. He has received no personal income from such sources.

1 Heller T, Heller D, Pattison S, Heller T. Ethical debate: Vaccination against mumps, measles, and rubella: is there case for deepening the debate? BMJ 2001;323:838-40. (13 October.)

\section{Authors' summary of responses}

EDITOR-Our ethical debate on measles mumps, and rubella (MMR) vaccine generated responses sent to us individually as well as rapid responses posted to bmj.com. We cipally on the research income they can

received 14 personal responses by email (and a further four responses from journalists, which are not considered further) and 17 public rapid responses were published by February 2001 (two further responses were posted after preparing this report). Nine of the 14 personal respondents and 10 of the 17 public respondents replied to our email request for further information.

Personal respondents were less likely than public respondents to be health professionals. Nine personal respondents mentioned MMR vaccine or autism in their family and seven declared an anti-MMR stance (table). Some commented positively on our courage (particularly that of TH)-for example, "There are too few people who are prepared to speak out and I thought you should know that there are others out there who feel deeply about the issue" and "Thank you for voicing your concerns about MMR. It is refreshing to see a member of the medical profession voice a valid concern."

Among the nine personal respondents who sent further information, four had previously responded to articles in the $B M J$ (compared with seven of the 10 public respondents) and six stated that a personal or professional interest had motivated their response (compared with four of the public respondents). Reasons for sending a personal response to us included a greater likelihood of getting a reply (four respondents) and a preference for private, direct discussion (three). Most of the public respondents wanted to join the debate and to seek a wider audience for this. None of the personal respondents made the point that herd immunity is important and that ethics discussions should balance individual and public responsibility.

Although the rapid response option on bmj.com offers the opportunity to join the debate on contentious issues such as MMR vaccine, it does not capture the responses of a small but important readership of the original publication. Those who responded to us personally seemed to share many of the public's concerns about, and perspectives on, MMR vaccination. ${ }^{23}$ Examining the views of those who respond in different ways to journal articles may offer insights into health controversies. Medical journals and

Characteristics of respondents and responses to ethical debate on vaccination against measles, mumps, and rubella (MMR)

\begin{tabular}{lcc} 
& $\begin{array}{c}\text { Personal response to authors } \\
(\mathbf{n = 1 4})\end{array}$ & $\begin{array}{c}\text { Public electronic response to } \\
\text { bmj.com (n=17) }\end{array}$ \\
\hline Respondent & 5 & 14 \\
\hline Health professional & 9 & 0 \\
\hline Personal experience of MMR or autism in family & 0 & 3 \\
\hline Professional experience of MMR or autism & 7 & 0 \\
\hline Declared anti-MMR stance & & 0 \\
\hline Response (type of comment) & 5 & 5 \\
\hline Personal positive comments to authors & 2 & 4 \\
\hline On science & 0 & 2 \\
\hline On responsibility to whole community (herd immunity) & 3 & \\
\hline On concerns over official cover up of adverse evidence & & \\
\hline
\end{tabular}

health policymakers might wish to explore the ways of doing this.

Dick Heller professor of public health

Evidence for Population Health Unit, School of Epidemiology and Health Sciences, University of Manchester Medical School, Manchester M13 9PT

Tom Heller senior lecturer

School of Health and Social Welfare, Open

University, Milton Keynes MK7 6AA

Stephen Pattison head

Department of Religious and Theological Studies, University of Cardiff, Cardiff CF10 3EU

Competing interests: None declared.

1 Health experts support MMR vaccine. Available at www ephu.man.ac.uk/GrandRounds/2001_11/

MMRPressRelease.htm

2 Jewell D. MMR and the age of unreason. Br J Gen Pract 2001;51:875-6.

3 Evans M, Stoddart H, Condon L, Freeman E, Gizzell M, Mullen R. Parents' perspectives on the MMR immunisation: a focus group study. Br J Gen Pract 2001;51:904-10.

\section{Physician assistants}

\section{Many general practitioners would welcome having physician assistants}

EDITOR-The possibility of creating an American style, intermediate medical practitioner or physician assistant role has been too long ignored in debates about shortages of trained medical staff in the NHS. In casting doubt on the appropriateness of this particular approach, however, Hutchinson et al lamentably fail to appreciate the scale of the problems currently faced by the NHS in providing effective primary medical care.

They state that more than half of all doctors are general practitioners. Not so. Half of all medical graduates may eventually finish their careers as general practitioners-an artefact of the way the medical labour market is organised-but general practitioners currently make up about $31 \%$ of all doctors. ${ }^{2}$ The number as a proportion of the medical workforce has been falling for years; and research examining the career preferences of junior doctors suggests that the difficulties may soon get worse.

Problems of recruitment in general practice, as the authors observe, are particularly acute in inner cities, which have never had much "doctor appeal." The backbone of the medical labour force in such neighbourhoods has come from the ranks of doctors who qualified in south Asia. More than 60\% of this group will shortly reach retirement age. Who will replace them? ${ }^{4}$

The government's current strategies aimed at addressing the undersupply of general practitioners, such as increasing places at medical school and offering doctors cash, either to enter general practice or delay retirement, are seriously flawed. ${ }^{5}$ Much more radical solutions are called for. The idea of physician assistants is a radical one, and it is time it was given serious consideration. It certainly deserves to be piloted and evaluated.

Recruitment of general practitioners is at crisis point. The creation of physician assistants could help reverse this situation. It would be a great shame if rhetoric about the 
need for "seamless care" and the breaking down of professional boundaries were to hamper efforts to establish a physician assistant role in the NHS and get in the way of providing effective medical care, especially among deprived populations.

The physician assistant role has been an overwhelming success in the United States. There is no reason why it could not be so here, given good will and the desire to see it succeed. ${ }^{5}$ My own research among general practitioners clearly indicates that they would regard physician assistants as a welcome addition to the primary care team.

Mike Gavin research associate in primary care Rusholme Academic Unit, School of Primary Care, Rusholme Health Centre, Manchester M14 5NP mike.gavin@man.ac.uk

1 Hutchinson L, Marks T, Pitillo M. The physician assistant: would the US model meet the needs of the NHS? $B M$ J 2001;323:1244-7. (24 November.)

2 Review Body on Doctors' and Dentists' Remuneration Review for 2001: written evidence from the health departments for Great Britain. London: Department of Health, 2000.

3 Lambert TW, Goldacre MJ, Edwards C, Parkhouse J. Career preferences of doctors who qualified in the United Kingdom in 1993 compared with those of doctors qualifying in 1974, 1977, 1980, and 1983. BMJ 1996:313:19-24.

Tayor DH Jr, Esmal A. Retrospetive analysis of cens

Taylor DH Jr, Esmail A. Retrospective analysis of censu data on general practitioners who qualified in

who will replace them? BMJ 1999;318:306-10. ‥ .

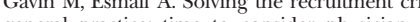
general practice: time to consider physician assistants? Social Policy and Adminstration (in press).

\section{American idea of physician assistants can be anglicised}

EDITOR-As a physician assistant educator from the United States completing a sabbatical with a medical school in the United Kingdom and the NHS, I am well placed to comment on Hutchinson et al's article. ${ }^{1}$

Shaw's concept of "two countries separated by a common language" applies to the United States and the United Kingdom. The education of doctors in the United States takes eight years from the time they leave school to the time they graduate from medical school. The article states that the education of physician assistants takes six years. With few school leavers becoming physician assistants, however, a better figure is the average length of core professional education for physician assistants (24-25 months) ${ }^{2}$; this is shorter than the evolving four year graduate entry programmes in medical schools in the United Kingdom.

Differences in the length of programmes reflect differences in the countries' overall education systems, not substantial variation in core training for physician assistants. American degree standards are less consistent then British ones, and assessment of experiential learning is uncommon. Education of physician assistants is competence based (not degree based) and accredited as such"; this matches the NHS plan's "skills escalator" concept (para. 9.18). ${ }^{4}$

The authors note that physician assistants neither "perform ... tasks of other therapists" nor "remove professional boundaries or barriers to expanding scope of practice." While some physician assistants perform such tasks (for example, rural physician assistants can perform basic $x$ ray examinations in the absence of a radiogra- pher), this is not a core function. The authors regard this negatively; it perpetuates a confusing blurring of new roles identified by the NHS plan and the Royal College of Physicians. $^{5}$

Importantly, the call for a "healthcare practitioner" (para. 9.15), analogous to American physician assistants, addresses one set of needs (access to primary care,junior doctor issues) whereas the "assistant practitioners" concept addresses needs of "other areas" (for example, shortages in the professions allied to medicine) (para. 9.14) A justifiable concern is that an overly generic practitioner, simultaneously combining the American physician assistant core with multiple assistant (profession allied to medicine) practitioner roles, might be a dangerous "Jack of all trades, master of none." The concept of healthcare practitioner in the United Kingdom must be evaluated solely against needs that it is intended to address. Physician assistants have proved their worth and flexibility in the United States but are not the solution to al ills.

Simply importing an American physician assistant "package" would not be an ideal British solution, but evidence suggests that physician assistants can be suitably anglicised to patients' benefit-presumably this is the ultimate goal.

William H Fenn professor

Western Michigan University, Kalamazoo, MI 49009, USA

fenn@wmich.edu

1 Hutchinson L, Marks T, Pittilo M. The physician assistant would the US model meet the needs of the NHS? $B M /$ 2001;323:1244-7. (24 November.)

2 American Academy of Physician Assistants. Facts at a glance, 6 Nov 2001. Available at www.aapa.org

3 Accreditation Review Commission on Education for the Physician Assistant. Accreditation standards for physicia assistant education. Marshfield, WI: ARC-PA, 2001.

Department of Health. The NHS plan: a plan for inuestment, a plan for reform. London: Stationery Office, 2000.

5 Orme M, Bloom S. Hospital doctors under pressure. Or the health con S. Hospital doctors under pressure: new roles for the health care workforce. London: Royal College of Phy-
sicians, 1999 .

\section{European working time directive for doctors in training}

\section{Reduction in juniors' hours abolishes concept of continuity of care}

EDITOR-The gloating editorial by Pickersgill, the chairperson of the BMA's Junior Doctors Committee, convinces me that the $B M J$ is now the magazine for the coffee table of the politically active lily-livered doctors who populate the NHS. ${ }^{1}$ The smile will be wiped off Pickersgill's face if ever he is unfortunate enough to need an operation.

The reduction in junior doctors' hours does not satisfy trainee surgeons' need for operative experience and abolishes the concept of continuity of care. All surgeons (trainees and consultants) understand that a patient deserves and requires continual care by the same firm for the duration of his or her admission. Pickersgill and others need to realise that trainee doctors' needs differ across the specialties and that many other professionals work long hours. It is time that the senate of the Royal Colleges of Surgeons said no to Europe's directives.

David Scott-Coombes consultant endocrine surgeon Department of Surgery, King's College Hospital, London SE5 9RS

David.Scott-Coombes@kcl.ac.uk

1 Pickersgill T. The European working time directive for doctors in training. BMJ 2001;323:1266. (1 December.)

\section{Profession needs to modernise surgical training}

EDITOR-To ensure better surgical training in shorter hours ${ }^{1}$ a more structured and focused approach must be adopted. With the introduction of the new deal, Calman report, and European working time directive, the time available to train a surgeon is now reduced by more than two thirds. Further reductions in working hours threaten to jeopardise the effective continuation of patient care and compromise training, resulting in inexperienced surgeons. Fundamental reform must now take place to guarantee high surgical standard.

We must separate service provision from training and learn from the healthcare systems in the United States and Europe, where qualified physician assistants (professionally trained non-medical staff) are employed routinely to share the workload with the junior staff.

Trainers who are willing to initiate change must give a strong, enthusiastic lead in improving training, which has long been unstructured, repetitive, and at times irrelevant to the specialty ambitions of trainees. ${ }^{2}$ The standards for surgical practice should be clearly monitored and enforced, and frequent formal independent assessment, such as the record of in-training assessments and assessment by the specialist advisory committees, will help. It is essential that both trainers and trainees are assessed, with the royal colleges encouraging all consultants to improve their training abilities. Good trainers should be recognised, and bad ones should be excluded from training programmes.

The organisation of theoretical training (at local or regional level) should ensure that specific topics are taught in coordinated lectures or courses, when trainees from the same deanery are free from clinical commitments. During practical training, ward rounds and outpatient clinics should be educational. In addition, trainees must have hands-on experience in the operating theatre, with proper supervision, instruction, and practice. This may be difficult to achieve in the NHS, which is already limited in time and resources. Consequently, an increased amount of training in surgical skills has to be done with simulators (for example, latex models of organs, laparoscopic boxes), anaesthetised animals (for laparoscopic and endovascular procedures), or computer generated virtual reality (for example, laparoscopy, endoscopy). ${ }^{3}$ Such facilities must be widely available to all trainees.

Finally, the assessment of operative skill needs to become more objective and 
independent. ${ }^{4}$ Assessment methods (such as the objective structured assessment of technical skills or the Imperial College surgical assessment device) are already available. Detecting underperformance early would allow further training and guidance. We need to reappraise, reform, and modernise surgical training rather than blame Europe for cutting junior doctors' working hours.

Y C Chan specialist registrar in general surgery, South-East Deanery

Department of Surgery, King's College Hospital, London SE5 9RS

ycchan88@hotmail.com

1 Pickersgill T. The European working time directive for doctors in training. $B M$ J 2001;323:1266. (1 December.)

2 Taffinder N. Better surgical training in shorter hours. $J R$ Soc Med 1999;92:329-31.

3 Torkington J, Smith SG, Rees BI, Darzi A. The role of simulation in surgical training. Ann R Coll Surg Engl 2000;82:88-94.

4 Darzi A, Datta V, Mackay S. The challenge of objective assessment of surgical skill. Am J Surg 2001;181:484-6.

\section{Improving outcomes in depression}

\section{Integrated solutions should not be provided at the expense of reduced participation of statutory sector}

EDITOR-An overview by experts in the field reasoning for and recommending the better quality and delivery of care to a substantial population is greatly to be welcomed. ${ }^{1} \mathrm{We}$ need a person centred, whole system approach, with medical management being but a part of the best practice "prescription." Early intervention and active management work for every other condition known to man and prevent the long term complications of potentially recurrent or chronic ill health, whether it be asthma, diabetes, hypertension, or depression. The cerebral dysfunction associated with depression (which is far more than a mood disorder) produces lost quality of life, disability, comorbidity, and somatisation-all of which cost the health, social, and employers' budgets billions of pounds a year and place a huge burden of work on practitioners of primary healthcare and social care.

The voluntary and private sectors also have a major part to play. However, integrated solutions should not be provided at the expense of reduced participation of the statutory sector, simply to enable government to keep taxation down or avoid responsibility for service provision under the guise of increasing the flexibility for local solutions.

The key educational message must also be that psychological issues themselves generate some $40 \%$ of consultations in general practice and should be dealt with as a priority at the beginning, not as a door handle exit strategy at the end. The national service framework for mental health underpins all the others and provides the template for the generic issues and highest common factor "doables" that weave through all of them, from information and communication strategies through to the necessity for attitudinal and behavioural change. Learning how to work more effectively together and moving towards a culture in which, if we are all agreed on something, then only one of us needs to go to the meeting, would contribute enormously to the mental wellbeing of service providers, let alone users.

Introducing depression management into general practitioners' management remit for chronic disease and their remuneration and commissioning system would also help to improve standards of care for this group of patients much more quickly. This must happen under the contractual arrangements of the new primary care trusts, and when it does, as a service user, I will be finally convinced that people are genuinely committed to doing something real, rather than rhetorical, about the care of this now extremely common, and for many, severe and enduring mental illness.

Chris Manning chief executive officer

Primary care Mental Health and Education (PriMHE), The Old Stables, 2A Laurel Avenue, Twickenham TW1 4JA

1 von Korff M, Goldberg D. Improving outcomes in depression. BMJ 2001;323:948-9. (27 October.)

\section{Practice of medicine should carry health warning}

EDITOR-The two doctors who wrote about their depressive illnesses should be congratulated. ${ }^{2} \mathrm{~A}$ few years ago admission of mental ill health by a doctor would have been unthinkable. A weight of evidence is, however, accumulating, which shows that the mental health of doctors is on average worse than the general population's. ${ }^{3}$

The reasons for this are complex but include factors specific to the young people who become doctors and to the job itself. Qualitative research has shown that some medical students are motivated to study medicine as a partial response to unconscious neurotic drives and unresolved conflicts from childhood. ${ }^{4}$ I have met ill doctors who have said that they entered the profession to put right distress or illness that occurred to them or members of their family during their childhood. Qualification did not resolve these emotional conflicts.

Doctors who have had mental ill health may be more empathic with patients with a similar illness, but empathic doctors are more likely to have emotional fatigue later in their careers. Doctors at greatest risk of such fatigue ("burnout") are those in general practice, psychiatry, oncology, and general medicine. High levels of self criticism, a perfectionist approach, and poor team working are also associated with poor mental health in doctors. ${ }^{5}$

The practice of good medicine is intellectually and emotionally demanding, and as the expectations of our patients, managers and professional bodies increase so do the pressures on doctors. It is no wonder that doctors are breaking down or leaving the profession prematurely. The practice of medicine is fraught with dangers and should carry a health warning for both patients and doctors.

C J M Poole consultant occupational physician Dudley Priority Health NHS Trust, Health Centre, Cross Street, Dudley, DY1 1RN

jon.poole@dudleyph-tr.wmids.nhs.uk

1 Anonymous. Why am I crying? BMJ 2001;323:1010. (27 October.)

2 McKall K. An insider's guide to depression. BMJ 2001;323:1011. (27 October.)

Williams S, Michie S, Pattani S. Improving the health of the NHS workforce. London: Nuffield Trust, 1998.

4 Maxwell H. Clinical psychotherapy for health professionals. London: Whurr, 2000.

5 Firth-Cozens J. Predicting stress in general practitioners:

10 year follow up postal survey. BMJ 1997;315:34-5.

\section{The future of rehabilitation}

\section{Rehabilitation should be regarded as scientific challenge}

EDITOR-Greenwood's editorial on the future of rehabilitation is a welcome sign that British neurologists have accepted restorative neurology as part of their discipline. ${ }^{1}$ But it suggests that their grasp of what rehabilitation is, and their understanding of the range of objectives that rehabilitation medicine seeks to achieve, are still uncertain.

For disabled people whose impairments cannot be reversed, rehabilitation involves processes that are clearly distinct from biological recovery, including learning, the acquisition of new skills, and the changing of behaviour. This is the case for the many non-neurological causes of impairment as well as the neurological ones.

Greenwood suggests that neurologists are far more disposed to accept published evidence that rehabilitation works now that they are able to view physical changes in the brain that might be taking place concurrently with it. If this is true they are seriously confusing two kinds of evidence.

Scientific study of the acquisition of skills and of the processes that enhance or obstruct it is potentially valuable in increasing our understanding of the processes involved and predicting how we might best promote them. But the demonstration of brain mechanisms at work is not proof that rehabilitation has been achieved. Other and different scientific approaches are necessary for that. Furthermore, Greenwood makes no mention of the influence that changes in a person's environment (especially the behaviour of others) can have on the overall outcome of rehabilitation-the wellbeing and social participation of the subject, not simply the eradication of biological impairments.

Finally, Greenwood's carping at rehabilitation medicine as a discipline is surely unjustified. He seems to think that four months' training in rehabilitation medicine is ample to enable neurologists to practise it on their patients but that one year's training in neurology is not nearly enough to allow specialists in rehabilitation medicine to promote rehabilitation in those with neurological disorders. 
The future of rehabilitation would look brighter if health professionals saw it as a scientific challenge in its own right to be met by interdisciplinary collaboration rather than as an opportunity for them to annexe clinical territory from others as soon as bits started to look interesting to them. Perhaps more neurologists could be prevailed on to attend meetings of the multidisciplinary Society for Research in Rehabilitation. There they could meet colleagues from the other disciplines already expert in this area, expand the old fashioned concepts of rehabilitation rehearsed in the editorial, and make a contribution to much needed progress in this important field.

Lindsay McLellan emeritus professor of rehabilitation Health and Rehabilitation Research Unit School of Health Professions and Rehabilitation Sciences, University of Southampton, Southampton SO16 6YD

dlm@soton.ac.uk

1 Greenwood R. The future of rehabilitation. BMJ 2001;323:1082-3. (10 November.)

\section{Specialist rehabilitation is best done by} those with skills in rehabilitation

EDITOR-Greenwood fails to address the title of his editorial and dismisses the contribution that physicians in rehabilitation medicine have made to the development of specialist rehabilitation in the United Kingdom over the past 15 years. ${ }^{1}$ Restorative neurology has exciting prospects, but patients will not benefit without specialist rehabilitation by physicians wholly engaged in the field. Physicians in rehabilitation medicine spend four years learning the principles and practice of rehabilitation, as well as its delivery through multiprofessional working. Twelve months in neurological rehabilitation is obligatory, but trainees intent on clinical practice spend further time during their programme addressing all aspects.

What does the health service need from its future rehabilitation professionals? Physicians and surgeons should provide rehabilitation for their own patients where possible, and it is thus desirable and appropriate that trainees in neurology should learn about it. This will teach them the basic principles but will not equip them to care for people with complex problems, who require a multiprofessional team to provide for them. The NHS needs to develop rehabilitation at primary care level for people living in the community but also to provide access to specialist facilities where appropriate.

New drug treatments may improve the functioning of people disabled by neurological disease, but both their successful participation in life and their wellbeing require doctors who are interested in rehabilitation. No apology should be made for this. When health care is provided by overstretched clinicians it is too easy to drop rehabilitation as an activity as it requires a lot of time and effort; mainstream specialty activities are seen as more pressing.

Rehabilitation medicine was created for this very reason, as rehabilitation was simply not done in the past by neurologists, rheumatologists, etc. Yes, let us hope for further advances in restorative neurology. But let us also see rehabilitation develop in both primary and acute secondary care. It should be complemented by specialist rehabilitation delivered by appropriately trained physicians-whether from rehabilitation medicine or clinical neurology-who have the time, skill, and resources, as well as the commitment and motivation, for the subject.

The changes to dual accreditation in neurology and rehabilitation medicine are to be welcomed, but effective specialist rehabilitation is best done by those with knowledge of and skills in rehabilitation rather than wholly concentrated in the underlying disease process. Let us address the future rehabilitative needs of the patients and not of the doctors.

Anthony B Ward consultant in rehabilitation medicine

North Staffordshire Hospital, Stoke on Trent ST6 7AG

anthony@bward2.freeserve.co.uk

1 Greenwood R. The future of rehabilitation. $B M$ 2001;323:1082-3. (10 November.)

\section{Risky drinking by both sexes should be tackled}

EdiTor-Having read Plant and Plant's letter on drinking by young British women, we present data on 12361 men and 20534 women aged 20-80 from the genetic environmental nature of emotional states in siblings (GENESiS) study. These data suggest that it is not just drinking by young British women that gives cause for concern: drinking by young British men does too.

The study is a questionnaire study based in the United Kingdom and includes measures on various mental health items as well as measures of alcohol consumption. Subjects were recruited in 1997-2000 through the Medical Research Council's general practice research framework. The participating general practitioners identified the names and addresses of all patients on their registers aged 20-55, excluding those with severe learning difficulties or psychotic illness. Siblings of these initial patients aged 20-80 were also recruited to take part.

The data provide no evidence of different trends developing in the drinking careers of women and men, as reported by Plant and Plant. In fact, the table shows that a consistently greater percentage of men than women drink at high risk levels $(\geqslant 51$ units a week for men, $\geqslant 35$ units a week for women). It also shows a pronounced reduction in numbers reporting risky drinking with increasing age.

Plant and Plant describe a sex difference in the pattern of drinking such that men are more likely to report heavy drinking in the age group 35-54 but women are more likely to do so in the age group 18-24. The GENESiS data show no such difference and indicate that heavy drinking is common and a cause for concern in both young men and young women.

The percentage of alcohol consumed non-sensibly (men $>4$ units a day, women $>3$ units a day) and heavily (men $>8$ units a day, women $>6$ units a day) was also calculated. In both sexes $88-90 \%$ of alcohol consumed by the 20-29 age group was consumed non-sensibly and 40-48\% was consumed heavily, figures that are similar to those in a recent report from the Department of Health.

It is thus vital that risky drinking by both men and women should be addressed in young adults. Tackling risky drinking behaviour in young people should be a key feature of the long overdue alcohol strategy.

Richard Williamson research worker Richard.Williamson@iop.kcl.ac.uk

Pak Sham professor

David Ball senior lecturer

Social, Genetic and Developmental Psychiatry

Research Centre, Institute of Psychiatry, King's

College London, London SE5 8AF

1 Plant M, Plant M. Heavy drinking by young British women gives cause for concern. BMJ 2001;323:1183. (17 November.)

2 Department of Health. Drinking: adults behaviour and knowledge in 2000. London: $\mathrm{DoH}, 2001$.

\section{Time has come for mandatory unit labelling}

EDITOR-The editorial by Ferner and Chambers illustrated both the difficulties inherent in calculating the number of units consumed and the dangers in excess alcohol consumption. ${ }^{1}$ So what should we do? Australia's commonsense and research based approach was to legislate for compulsory labelling of alcoholic beverages with "standard drinks." In the United Kingdom we are at least six years behind Australia, and only those drinks companies and retailers in agreement with unit labelling are taking part in a voluntary scheme launched in 1999 . Some companies could be praised for their clear bold labelling, whereas others employ tiny difficult to read symbols of dubious use.

We called for the government to legislate for bold unit labelling on the front of alcoholic drink containers and this has now been supported by the Drug and Therapeutics Bulletin. ${ }^{23}$ A natural conclusion for Ferner and Chambers would also be to call for unit labelling.

After more than a decade of offering health advice on alcohol in terms of units, health professionals should end the confusion. The BMA and the royal colleges should

Numbers (percentages) of all subjects drinking at high risk levels

\begin{tabular}{lcccccccccccc}
\multicolumn{10}{c}{ Age (years) } \\
\cline { 2 - 12 } & $\mathbf{2 0 - 2 4}$ & $\mathbf{2 5 - 2 9}$ & $\mathbf{3 0 - 3 4}$ & $\mathbf{3 5 - 3 9}$ & $\mathbf{4 0 - 4 4}$ & $\mathbf{4 5 - 4 9}$ & $\mathbf{5 0 - 5 4}$ & $\mathbf{5 5 - 5 9}$ & $\mathbf{6 0 - 6 4}$ & $\mathbf{6 5 - 6 9}$ & $\mathbf{7 0 - 7 4}$ & $\geqslant \mathbf{7 5}$ \\
\hline Male & $39(13)$ & $93(10)$ & $86(6)$ & $80(5)$ & $97(5)$ & $74(4)$ & $87(4)$ & $61(4)$ & $7(6)$ & $1(4)$ & 0 & 0 \\
\hline Female & $36(6)$ & $98(5)$ & $87(3)$ & $79(3)$ & $91(3)$ & $103(4)$ & $92(3)$ & $30(1)$ & $1(1)$ & 0 & 0 & $1(13)$ \\
\hline
\end{tabular}


be calling on the government to introduce compulsory unit labelling.

Phil J Webster-Harrison general practitioner Port View Surgery, Saltash PL12 4BU pjwh@globalnet.co.uk

Andy G Barton coordinator

Plymouth and South Devon Research and

Development Support Unit, Plymouth

Postgraduate Medical School, Plymouth PL6 8BX

1 Ferner RE, Chambers J. Alcohol intake: measure for measure. BMJ 2001:323:1439-40. (22-29 December.)

2 Webster-Harrison PJ, Barton AG, Berton SM, Anderson SD. General practitioners' and practice nurses' knowledge k. BrJ Gen Pract

3 Getting tight on units of alcohol. Drug Ther Bull 2001;39:95.

\section{Child outpatient non-attendance may indicate welfare concerns}

EDITOR-Much effort has been put into reducing the high rates of non-attendance at outpatient clinics. ${ }^{12}$ Currently there is a drive to improve the quality of outpatient services, which in itself will improve attendance rates. The laudable recommendations of the Clinical Standard Advisory Group approach the problem from a health perspective. ${ }^{3}$ Sharp and Hamilton's editorial rehearses some of these strategies and highlights the magnitude of the problem in deprived populations. ${ }^{4}$ Social circumstances are a major influence on health, and we explored this in an audit of outpatient paediatric non-attenders.

We performed a retrospective audit of all paediatric outpatients attending a district general hospital in a deprived area of London over six months from January to June 2000. Of 2183 appointments, 685 were missed. Altogether, 589 were for children living in the local borough. Of these, 218 were for patients known on the social services database (157 were themselves on the database, while in the remaining 61 cases other family members were listed). Of the 157 patients, 38 were listed on the child protection index, of whom eight were on the current child protection register.

Thus we found that one third of the outpatient non-attenders were known to social services. Our audit illustrates why we must consider non-attendance within the wider social context and the importance of close liaison with social services. Medical staff must recognise non-attendance as a possible indicator of child welfare concerns and make contact with social services. This audit shows that good interagency working (encouraged by the Health Act 1999, the NHS Plan, and the Department of Health) is justifiably a high priority.

Mando Watson consultant paediatrician

St Mary's Hospital, London W2 1NY

Mando.Watson@st-marys.nhs.uk

Martin Forshaw team manager

Children and Families, Social Work Department, West Middlesex Hospital, Isleworth, Middlesex TW7 6AF
1 Stone CA, Palmer JH, Saxby PJ, Devaraj VS. Reducing non-attendance at outpatient clinics. J R Soc Med 1999;92:114-8

2 Gatrad AR. A completed audit to reduce hospital outpatients non-attendance rates. Arch Dis Child 2000;82:59-61

3 Dodd K, Newton J. Outpatient services for children. Arch Dis Child 2001;84:283-5.

4 Sharp D, Hamilton W. Non-attendance at general practice and outpatient clinics. BMJ 2001;323:1081-2. (10 November.)

\section{Hospitals must not be closed without considering all factors}

Editor-The article by Lock, the former member of parliament for Kidderminster, who is upset about losing his parliamentary seat having failed to convince his constituents that they did not need their local hospital, is interesting. ${ }^{1}$ It shows the chasm that has opened up between politicians and the general public and the tight compartments into which the government confines decision making, despite the promise of joined up government. The only consideration mentioned by Lock is medical safety in Kidderminster Hospital, and the only people he seems to have consulted are doctors, and yet he remains confident that he is right and 28000 voters in Kidderminster are wrong.

What about other relevant factors? Can the alternative hospital handle the increased load? Is it accessible? Are any bottlenecks likely to separate the people of Kidderminster from their accident and emergency cover? Can the ambulance service handle the increased load and guarantee to deliver patients on time? Are essential staff likely to be retained within the NHS? Is the population in the catchment area increasing or decreasing? Is there potential for major disasters in the area? Can these be handled once the target hospital is closed? There is no medical safety in having the best manned and equipped hospital in the country if it cannot do the job.

The Kidderminster experience is almost a repeat of what has happened in Gosport. The main differences are that our local hospital, the Royal Hospital Haslar, is also the United Kingdom's last military hospital, and our member of parliament listened to his constituents and is leading the "Save Haslar" campaign. As in Kidderminster, the public consultation revealed little common ground between platform and public, and as usual the public proved to be right. Lack of capacity to cope with additional patients at neighbouring hospitals has forced the reopening of much of Haslar Hospital. This will become even more important as a massive house building programme attracts thousands more people into the catchment area. The accident and emergency department has not yet been restored, but everyone knows that the current provision is inadequate. The prospect of a seriously ill patient from Gosport reaching accident and emergency in time, along the highly congested single lane road, is highly speculative.

Politicians must start listening to the public, and all relevant factors must be fully considered before such important decisions as hospital closures are taken. The closure of Haslar, which has caused so much anxiety and distress in this district, was decided unilaterally by the Ministry of Defence.

John Parry retired

20 Crescent Road, Alverstoke, Gosport, Hampshire PO12 2DH

1 Lock D. Stuck in the middle? BMJ 2001;323:1195. (17 November.)

\section{Death after inserting Hickman line was probably avoidable}

EDITOR-The death of a 15 year old girl in 1998 due to a complication of inserting a Hickman line, and the ensuing court case in December last year, highlight the considerable morbidity and occasional mortality associated with central venous access. In one year alone the Scottish audit of surgical mortality identified four deaths directly attributable to insertion of a venous line. A greater number of patients have their serious medical conditions further complicated by iatrogenic pneumothorax; the true extent of these problems is unknown.

For the past 15 years this hospital has provided a dedicated weekly operation list for the insertion of central lines, placing over 250 each year and often dealing with highly complex situations in patients who have had many previous lines and patients who are referred from other hospitals. We have not had one death related to insertion of a line, and pneumothorax is virtually unknown. We use local anaesthesia, ultrasound scanning to identify the right internal jugular vein in most cases, and a closed "peel cath" technique.

Why did this complication occur, and can it be eradicated? I believe that a major factor is the design of the equipment, and in particular the length of the introducing dilator and peel cath. The internal jugular vein in the neck is always within easy reach of a standard green needle, which typically measures $3.5 \mathrm{~cm}$ in length. However, the typical length of the introducing dilator provided by most manufacturers for line insertion is almost $20 \mathrm{~cm}$, so when it is placed fully within the vein in the neck as required its tip is lying within the heart.

A dilator of this length is rarely needed. If we could persuade manufacturers to reduce its length to $10 \mathrm{~cm}$ in standard packs then the complication from which this patient died simply could not occur. I drew this fact to the attention of the Scottish Home and Health Department when the case was first reported, but it declined to take the matter any further.

S J Nixon consultant surgeon

Western General Hospital, Edinburgh EH4 2XU

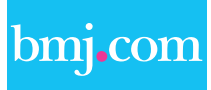

\section{Rapid responses}

Correspondence submitted electronically

is available on our website 